\title{
Cultural beliefs about breast cancer in Vietnamese women
}

\author{
Jong Gun Kim ${ }^{1}$, Hye Chong Hong ${ }^{2^{*}}$ (D) Hyeonkyeong Lee ${ }^{3}$, Carol Estwing Ferrans ${ }^{4}$ and Eun-Mi Kim ${ }^{5}$
}

\begin{abstract}
Background: This study examined factors influencing cultural beliefs associated with later-stage detection of breast cancer and determined what factors influence those cultural beliefs in Vietnamese women residing in a rural Vietnamese community.

Methods: A cross-sectional survey was conducted with 289 women aged 20-64 years from 12 villages using a selfadministered structured questionnaire. Cultural beliefs were measured with a 13-item cultural beliefs scale consisting of four domains_characteristics of breast lumps, self-help techniques, faith-based beliefs, and futility of treatment. Data were collected in February 2017 and analyzed using chi-square tests, nonparametric tests, Fisher's exact tests, and multiple linear regression analyses with SPSS/WIN 24.0 statistical software.
\end{abstract}

Results: Although the total score was relatively low (3.4 out of 13), cultural beliefs that could contribute to laterstage breast cancer were identified. Younger women $(\beta=.15, p=.016)$ and women with a lower income $(\beta=.21$, $p<.001)$ held more erroneous cultural beliefs as compared to their counterparts. Most women believed they would not get breast cancer if they took care of themselves. More than one-third held cultural beliefs about breast lumps, thinking they would need to be painful and/or actively growing to be breast cancer.

Conclusions: The results support the urgent need for education concerning breast cancer health promotion, including breast cancer assessment as well as guidance on evidence-based and up-to-date detection measures to change rural Vietnamese women's cultural beliefs.

Keywords: Breast cancer, Cultural beliefs, Health behavior, Public health, Nursing education, Vietnamese women.

\section{Background}

Breast cancer is the most frequently occurring cancer in women, leading to the highest number of cancer-related deaths globally. Breast cancer comprised about 2.4 million of all cancer cases in 2015 [1], which was a $43 \%$ increase from 2005. The incidence of breast cancer is higher in developed countries; however, this increasing trend appears in most regions of the world, including Vietnam [1].

Although the breast cancer incidence in Vietnamese women is lower compared to other Asian countries, the incidence has increased owing to decreased fertility rates and increased obesity in Vietnamese populations [2]. The National Cancer Control Program was introduced in selected regions of Vietnam to reduce mortality and

\footnotetext{
* Correspondence: julieh@cau.ac.kr

${ }^{2}$ Red Cross College of Nursing, Chung-Ang University, 84 Heukseok-ro,

Dongjak-ku, room 401-3, building 106, Seoul 06974, South Korea

Full list of author information is available at the end of the article
}

morbidity and to improve the quality of life of patients with cancer [3], and it has established cancer registries and initiated an organized screening program designed to detect breast cancer [3]. However, breast cancer screening (BCS) programs have mostly been implemented with limited populations such as women who reside in urban areas, who can afford the cost of screening because of the lack of a systematic, nation-wide, screening policy [4].

As reported in earlier studies, cultural factors such as conceptualizations of health, illness, beliefs, and values can influence women's BCS practices in certain populations [5-7]. Among women living in Vietnam, the level of BCS is reported to be relatively low. In a national screening program conducted in 2008-2010, less than $10 \%$ of women aged $30-60$ years from 10 provinces of Vietnam had a chance to take clinical breast examinations [8]. Only a small proportion of Vietnamese women

(c) The Author(s). 2019 Open Access This article is distributed under the terms of the Creative Commons Attribution 4.0 International License (http://creativecommons.org/licenses/by/4.0/), which permits unrestricted use, distribution, and 
in transnational marriages living in Taiwan had performed a breast self-examination (BSE) during the past year $(25.6 \%)$ - a figure which is even lower on a monthly basis (7.6\%) -and $6.8 \%$ of this population underwent mammography during the past 2 years [9]. These low levels of BCS lead to breast cancer symptoms going undetected, contributing to late-stage diagnosis of breast cancer and subsequent poorer outcomes and death [10]. Although a low awareness and lack of knowledge concerning BCS appear to be a key barrier to BCS in women residing in low- and middle-income countries [11], there is still a lack of understanding of the perceptions and attitudes toward BCS among women living in rural Vietnamese areas.

Like women in many other Asian nations, Vietnamese women are in a traditional society that more closely follows ancestral conceptualizations of gender roles. Studies have reported that older Asian women hold more traditional health beliefs, such as fatalism, which influence their perceptions of health, illness, and the use of preventive healthcare methods [12]. Rather than practicing preventative techniques, Asian women tend to believe that events such as falling ill are pre-determined [13]. For Vietnamese women living in the United States, gender roles (i.e., femininity) are associated with a higher probability of having a clinical breast exam, but only for those women who were highly acculturated to the U.S. [14]. However, that same study also found that Vietnamese women in the U.S. with higher collectivist values showed higher efficacy for BCS because these women were motivated to perform BCS and maintain their health owing to their key family roles [14]. These findings demonstrate the importance of culture in BCS practices among Vietnamese women.

Culture is defined as a multidimensional set of shared and socially transmitted ideas about the world, which are passed down from generation to generation $[15,16]$. Cultural beliefs are considered a determinant for perceptions of health risks and the practice of healthpromoting behaviors in diverse populations [17]. Cultural beliefs related to breast cancer are a critical factor in women's decisions concerning BCS practices in traditional societies. In a systemic review of 23 studies associated with the influence of cultural factors, the experiences of South Asian women with breast cancer were culturally linked to cancer-related stigma, familial experiences, reliance on religion, and low prioritization of women's issues in comparison to Western women [12]. Further, previous studies showed that cultural beliefs differ by socio-demographic factors such as age, education level, and healthcare insurance [18].

A recent scoping review of breast cancer in Vietnam suggests that patients' perceptions of social and cultural aspects related to the later detection of breast cancer should be explored to design appropriate interventions [4]. To our knowledge, however, no studies have specifically addressed the cultural beliefs about breast cancer among women residing in Vietnam. Therefore, we investigated Vietnamese women's cultural beliefs concerning breast cancer and determined the influential factors per socio-demographic characteristics in a rural Vietnamese community.

\section{Methods}

\section{Design and sample}

A community-based, cross-sectional survey was conducted in a district of the central coastal region of Vietnam, Cam Thuy, which has a population of 3500 . Cam Thuy is a rural, impoverished community in Quang Tri Province. The survey targeted women aged 20 to 64 years across 12 villages. This study is part of a group of research projects that examine BCS practices and their determinants. Three-hundred twenty-six women voluntarily agreed to participate in the study. A detailed sample calculation was discussed in the primary research that examined the BCS practices and their determinants [19].

\section{Instruments}

Cultural beliefs were measured with the cultural beliefs scale developed by Ferrans $[20,21]$. The scale was designed to measure the extent that cultural beliefs act as barriers to early detection, and thus contribute to a diagnosis of later-stage breast cancer for African American, Hispanic, and Caucasian women. The scale comprises 17 items across four content areas: breast lumps $(n=4)$, self-help techniques $(n=4)$, faith-based beliefs $(n=4)$, and futility of treatment $(n=5)$. Each item was measured by a dichotomous response (true or false). Four items related to mammogram were excluded as mammogram service is not available in this study setting. Thus, the total score ranges from 0 to 13 , with higher scores indicating that participants hold a greater number of cultural beliefs, while lower scores indicate that respondents hold fewer cultural beliefs.

The cultural beliefs scale was translated using a committee approach translation [22]. Three Vietnamese bilingual experts individually translated the questionnaire and reviewed the Vietnamese version of the questionnaire to modify the translation during the design meeting. These three experts were professors in universities in Vietnam who were familiar with Vietnamese culture and proficient in English. After these processes, some modifications were made by the principal investigators and another local expert in response to feedback from participants through cognitive interviews with five Vietnamese women. The copy of the Vietnamese cultural beliefs scale is available as a Additional file 1 


\section{Data collection}

Data were collected in collaboration with the local Women's Council. The study purpose and survey methods were explained to the president of the Women's Union, and they agreed to assist with data collection. Subsequently, the female leaders from the 12 villages were recruited from the local Women's Union and trained by local experts to collect the data. Training included explanations of the study objectives and design, how to describe the questionnaire to participants, and how to obtain consent.

Data collectors visited individuals' homes and common community areas, such as markets, local events, and member meetings, and distributed questionnaires after explaining the purpose of the study. The survey was self-administered. After collecting participants' responses in private envelopes, a small gift was provided to all participants. Data collection was performed from February 8-13, 2017.

\section{Data analysis}

Demographic characteristics were calculated using descriptive statistics. Differences in cultural beliefs by age group were tested using chi-square tests and Fisher's exact tests. Age, income, education, marital status, having medical insurance, menopause status, and history of a breast disease diagnosis did not satisfy the assumption of normal distribution $(p<.05)$ when Shapiro-Wilk's regularity test was conducted; therefore, the MannWhitney U test and Kruskal-Wallis test were conducted with Tukey's post-hoc test post analysis. The cut-off for the monthly average income was based on the report from the Vietnam organization in 2017 [23]. In addition, multiple linear regression analysis was conducted to determine the factors affecting cultural beliefs. The assumption of multicollinearity was met because the variance inflation factor values of all variables were less than 10 (1.04-1.77), and the values of tolerance were greater than $0.1(0.56-0.95)$. Statistical software SPSS ver. Twenty four for Windows was used for statistical analyses, with the level of significance set at $5 \%$.

\section{Results}

\section{Participants' general characteristics}

We carefully reviewed each questionnaire received and excluded 37 participants with insufficient or invalid answers; thus, the data from 289 women were included in the final analysis. As shown in Table 1, more than half of the participants (57.8\%) were between 20 and 39 years of age. Notably, nearly $80 \%$ of the participants had graduated from secondary school which was $\mathrm{s}$ lower than 2010-2011 average (94.3\%) of Quang Tri in general [24], whereas $4.8 \%$ of the participants had no formal education. The majority of subjects were married (90.7\%), had
Table 1 Differences in Cultural Beliefs by General Characteristics $(N=289)$

\begin{tabular}{|c|c|c|c|}
\hline \multirow[t]{2}{*}{ Characteristic } & \multirow[t]{2}{*}{$n(\%)$} & \multicolumn{2}{|c|}{ Cultural beliefs } \\
\hline & & $\overline{M \pm S D}$ & $U$ or $x^{2}(p$ values) \\
\hline \multicolumn{4}{|l|}{ Age (years) } \\
\hline Young: 20-39 & $167(57.8)$ & $3.62 \pm 1.68$ & 8169.5 \\
\hline Old: 40-64 & $122(42.2)$ & $3.07 \pm 1.64$ & $(.004)$ \\
\hline \multicolumn{4}{|l|}{ Income level } \\
\hline$<\mathrm{AMW}$ & $201(69.6)$ & $3.62 \pm 1.60$ & 6605.0 \\
\hline$\geq \mathrm{AMW}$ & $88(30.4)$ & $2.86 \pm 1.74$ & $(<.001)$ \\
\hline \multicolumn{4}{|l|}{ Education level } \\
\hline$\geq$ Secondary & $224(77.6)$ & $3.39 \pm 1.68$ & 15.84 \\
\hline Primary school & $51(17.6)$ & $2.86 \pm 1.38$ & $(.027)$ \\
\hline No education & $14(4.8)$ & $4.00 \pm 1.70$ & \\
\hline \multicolumn{4}{|l|}{ Marital status } \\
\hline Married & $262(90.7)$ & $3.35 \pm 1.67$ & 3031.5 \\
\hline Not married & $27(9.3)$ & $3.77 \pm 1.80$ & $(.215)$ \\
\hline \multicolumn{4}{|c|}{ Having medical insurance } \\
\hline Yes & $248(85.8)$ & $3.39 \pm 1.75$ & 5035.5 \\
\hline No & $41(14.2)$ & $3.39 \pm 1.20$ & $(.921)$ \\
\hline \multicolumn{4}{|l|}{ Menopause status } \\
\hline Yes & $46(15.9)$ & $3.39 \pm 1.67$ & 5473.5 \\
\hline No & $243(84.1)$ & $3.39 \pm 1.69$ & $(.822)$ \\
\hline \multicolumn{4}{|c|}{ Diagnosed with a breast disease } \\
\hline Yes & $17(5.9)$ & $2.82 \pm 1.18$ & 1820.5 \\
\hline No & $272(94.1)$ & $3.42 \pm 1.70$ & $(.136)$ \\
\hline
\end{tabular}

medical insurance $(85.8 \%)$, were not undergoing menopause $(84.1 \%)$, and had no history of breast disease (94.1\%).

\section{Differences in cultural beliefs by general characteristics} Participants' self-reported cultural beliefs significantly differed by age, income, and education $(p<0.05)$ (Table 1). Specifically, the average cultural belief scores of participants under 40 years were significantly higher than the cultural belief scores of participants over 40 years $(\mathrm{U}=8169.5, p=.004)$. Level of education were significantly related to cultural beliefs $\left(X^{2}=15.84\right.$, $p=.027$ ), but there was no difference between groups. Women who earned below average monthly wages $(<2,650,000$ Vietnam dollar; VND) [23] had higher cultural belief scores than those with higher income levels $(\mathrm{U}=6605.0, p<.001)$.

AMW. average monthly wage $(2,650,000 \mathrm{VND}=$ 116.25 USD), $\mathrm{M}=$ mean; $\mathrm{SD}=$ standard deviation .

\section{Levels of cultural beliefs}

As shown in Table 2, participants' mean cultural beliefs scores were low (3.4 out of 13). By item, the percentage 
Table 2 Participants' Levels of Cultural Beliefs $(N=289)$

\begin{tabular}{|c|c|c|c|}
\hline \multirow[t]{2}{*}{ Domain } & \multirow[t]{2}{*}{ Item } & \multicolumn{2}{|c|}{ Response $\mathrm{n}(\%)$} \\
\hline & & True & False \\
\hline \multirow[t]{3}{*}{$\begin{array}{l}\text { I. Breast lump } \\
\text { characteristics }\end{array}$} & 1. If a breast lump is not painful, it is not cancer. & $\begin{array}{l}100 \\
(34.6)\end{array}$ & $\begin{array}{l}189 \\
(65.4)\end{array}$ \\
\hline & 2. If a breast lump does not get bigger, it is not cancer. & $\begin{array}{l}109 \\
(37.7)\end{array}$ & $\begin{array}{l}180 \\
(62.3)\end{array}$ \\
\hline & 3. If a breast lump is touched/pressed often, it will turn out to be breast cancer. & $26(9.0)$ & $\begin{array}{l}263 \\
(91.1)\end{array}$ \\
\hline \multirow[t]{3}{*}{ II. Self-help techniques } & 5. The more you worry about breast cancer, the more likely you will get it. & $23(8.0)$ & $\begin{array}{l}266 \\
(92.0)\end{array}$ \\
\hline & 6. If you take good care of yourself, you won't get breast cancer. & $\begin{array}{l}181 \\
(62.6)\end{array}$ & $\begin{array}{l}108 \\
(37.4)\end{array}$ \\
\hline & 13. If you have a breast lump, a "natural" remedy can help to get rid of it. & $\begin{array}{l}42 \\
(14.5)\end{array}$ & $\begin{array}{l}247 \\
(85.5)\end{array}$ \\
\hline \multirow[t]{3}{*}{ III. Faith-based beliefs } & 7. Faith in God can protect you from breast cancer. & $15(5.2)$ & $\begin{array}{l}274 \\
(94.8)\end{array}$ \\
\hline & 10. If you pray enough, sometimes breast lumps will disappear. & $4(1.4)$ & $\begin{array}{l}285 \\
(98.6)\end{array}$ \\
\hline & 14. If a woman has enough faith in God, she won't need treatment for breast cancer. & - & $\begin{array}{l}289 \\
(100.0)\end{array}$ \\
\hline \multirow[t]{4}{*}{ IV. Futility of treatment } & 11. If breast cancer is cut open in surgery, it will grow faster. & $18(6.2)$ & $\begin{array}{l}271 \\
(93.8)\end{array}$ \\
\hline & 15. If a woman is poor, she will not get cured from cancer because she won't get the best treatment. & $\begin{array}{l}108 \\
(37.4)\end{array}$ & $\begin{array}{l}181 \\
(62.6)\end{array}$ \\
\hline & *16. If breast cancer is treated correctly, it can be cured. & $\begin{array}{l}264 \\
(91.3)\end{array}$ & $25(8.7)$ \\
\hline & $\begin{array}{l}\text { 17. It doesn't really matter if you get treated for breast cancer, because if you get cancer, it will kill } \\
\text { you sooner or later. }\end{array}$ & $\begin{array}{l}90 \\
(31.1)\end{array}$ & $\begin{array}{l}199 \\
(68.9)\end{array}$ \\
\hline \multicolumn{2}{|l|}{ Total mean score } & 3.4 & - \\
\hline
\end{tabular}

*Reverse coded

of responses of "true" ranged from 1.4 to $91.3 \%$. The most agreed item was "If breast cancer is treated correctly, it can be cured" (91.3\%) in domain IV (futility of treatment). About $63 \%$ of women agreed on the item "If you take good care of yourself, you won't get breast cancer," in domain II (self-help techniques). No one gave a response of "true" to an item stating that, "If a woman has enough faith in God, she won't need treatment for breast cancer" in domain III (faith-based beliefs), and only a few women gave responses of "true" to the other two items in domain III.

Table 3 shows differing responses between younger (aged 20-39 years) and older (40-64 years) participants concerning cultural beliefs regarding breast cancer. Cultural beliefs involving several items across three domains showed significant age-group differences. Younger women showed a significantly lower level of cultural belief for, "If a breast lump does not get bigger, it is not cancer" than did older women $\left(\mathrm{X}^{2}=11.85, p=.001\right)$. Moreover, significantly more women in the younger group believed, "If you take good care of yourself, you won't get breast cancer" $\left(\mathrm{X}^{2}=7.88, p=.005\right)$ and, "If a woman is poor, she won't get cured from cancer, because she won't get the best treatment" to be true as compared to women in the older group $\left(\mathrm{X}^{2}=5.57, p=.018\right)$. The item, "If you have a breast lump, a natural remedy can help to get rid of it" was perceived as "true" with a marginally higher percentage in the younger women in comparison to the older women $\left(\mathrm{X}^{2}=3.75, p=.053\right)$.

The multiple linear regression analysis (Table 4) revealed that age and income level significantly affected women's cultural beliefs related to breast cancer. Women with a lower level of cultural beliefs were younger ( $<40$ years) $(\beta=.15, p=.016)$ and with a lower income $(\beta=.21, p<.001)$ in comparison to the reference group when other variables were controlled for. These factors explained $8.3 \%$ of cultural beliefs in the context of breast cancer reported by Vietnamese women.

\section{Discussion}

To improve BCS among Vietnamese women, it is imperative to explore the factors affecting their cultural beliefs in the context of breast cancer. This study evaluated the relationships among socio-demographic variables and cultural beliefs for BCS behaviors in Vietnamese women residing in rural Vietnam. This study is 
Table 3 Differences in Cultural Beliefs by Age Group $(N=289)$

\begin{tabular}{|c|c|c|c|c|c|c|}
\hline \multirow[t]{2}{*}{ Domain } & \multirow[t]{2}{*}{ Item } & \multicolumn{2}{|c|}{ Younger n (\%) } & \multicolumn{2}{|c|}{ Older n (\%) } & \multirow{2}{*}{$\begin{array}{l}x^{2}(p \\
\text { values) }\end{array}$} \\
\hline & & True & False & True & False & \\
\hline \multirow[t]{3}{*}{ I. Breast lump characteristics } & 1 & $59(35.3)$ & $108(64.7)$ & 41 (33.6) & $81(66.4)$ & $.09(.761)$ \\
\hline & 2 & $77(46.1)$ & $90(53.9)$ & $32(26.2)$ & $90(73.8)$ & $11.85(.001)$ \\
\hline & 3 & $11(6.6)$ & $156(93.4)$ & $15(12.3)$ & $107(87.7)$ & $3.53(.060)$ \\
\hline \multirow[t]{3}{*}{ II. Self-help techniques } & 5 & $12(7.2)$ & $155(92.8)$ & $11(9.0)$ & $111(91.0)$ & $.32(.570)$ \\
\hline & 6 & $116(69.5)$ & $51(30.5)$ & $65(53.3)$ & $57(46.7)$ & $7.88(.005)$ \\
\hline & 13 & $30(18.0)$ & $137(82.0)$ & $12(9.8)$ & $110(90.2)$ & $3.75(.053)$ \\
\hline \multirow[t]{3}{*}{ III. Faith-based beliefs } & 7 & $10(5.8)$ & $161(94.2)$ & $5(4.0)$ & $120(96.0)$ & $-\left(.595^{\mathrm{a}}\right)$ \\
\hline & 10 & $2(1.2)$ & $165(98.8)$ & $2(1.6)$ & $120(98.4)$ & $-\left(1.000^{\mathrm{a}}\right)$ \\
\hline & 14 & - & $167(100.0)$ & - & $122(100.0)$ & - \\
\hline \multirow[t]{4}{*}{ IV. Futility of treatment } & 11 & $7(4.2)$ & $160(95.8)$ & $11(9.0)$ & $111(91.0)$ & $2.81(.094)$ \\
\hline & 15 & $72(43.1)$ & 95 (56.9) & $36(29.5)$ & $86(70.5)$ & $5.57(.018)$ \\
\hline & 16 & 157 (94.0) & $10(6.0)$ & $107(87.7)$ & 15 (12.3) & $3.54(.060)$ \\
\hline & 17 & $52(31.1)$ & 115 (68.9) & $38(31.1)$ & $84(68.9)$ & $.00(.999)$ \\
\hline
\end{tabular}

${ }^{\text {a Fisher's exact test }}$

valuable in that it is the first to measure certain cultural beliefs of Vietnamese women, which can problematically contribute to late detection of breast cancer.

Contrary to expectations, we found that women's total cultural beliefs scores were low on average (3.4 out of 13) among Vietnamese women living in a rural areas. However, a considerable number of participants indicated that they believed several erroneous statements regarding breast lumps, self-help techniques, and futility of treatment for breast cancer. According to culturally sensitive mid-range theories, the strength of cultural beliefs, identity, and values that mediate risk perceptionssuch as risk attention and risk awareness-influence health-promoting behaviors [25]. Moreover, previous theories have clearly shown the influence of culture on health behaviors insofar as cultural beliefs triggering or prohibiting certain self-care behaviors in individuals with chronic illnesses $[17,26]$. As proposed in a theory based on the cultural determinants of help seeking [27], culturally held beliefs about health problems influence helpseeking behaviors in various sample populations, which has significant consequences on disease incidence

Table 4 Multiple Linear Regression Analysis for Factors Associated with Cultural Beliefs $(N=289)$

\begin{tabular}{lll}
\hline Variable & ßeta & $P$ values \\
\hline Younger age group (ref: older age group) & .15 & .016 \\
Lower AMW (ref: AMW or higher) & .21 & $<.001$ \\
Primary school (ref: no education) & -.04 & .562 \\
Secondary school or higher (ref: no education) & .07 & .314 \\
Having medical insurance (ref: yes) & -.04 & .492 \\
\hline
\end{tabular}

$\mathrm{F}=5.13, \mathrm{R}^{2}=.083, p<.001$

Ref $=$ reference group; $A M W$ average monthly wage worldwide. Thus, the current findings are useful for designing culturally appropriate interventions for this study population.

Regarding differences in cultural beliefs between younger and older women, however, this study showed that younger women had lower levels of cultural beliefs about breast cancer than did older women, including the characteristics of breast lumps. Previous studies have shown that cultural beliefs about breast lumps are much more common in women who are typically defined as disadvantaged population with lower socioeconomic status and less access to healthcare services [28]. Unlike women in Western countries who are diagnosed with breast cancer at a relatively early stage, many cases of breast cancer in Vietnamese women aged 45-55 years are found at a later stage [29]. Thus, women aged younger than 40 years are addressed as a priority population for education on the importance of BCS and the encouragement of BCS adherence. However, since the target women in this study resided in an underdeveloped community with limited health resources, even younger women might have lower awareness of BCS for the early detection of breast cancer. Consistently, Liu and colleagues [30] also showed that about three-quarters of young women aged 25-44years who lived in rural China, where medical access was limited and health screening was not universal, had poor awareness levels of BCS.

It is noteworthy that younger women were twice as likely as older women to agree with the statement, "If a breast lump does not get bigger, it is not cancer." As suggested by Lin and colleagues [31], this might be partly due to a lack of information from healthcare providers, messaging that is difficult to understand, or 
misinterpreted experiences. These cultural beliefs may result in a fear of breast cancer diagnosis that inhibits BCS. In fact, women in Asian societies often express fears that breast cancer diagnosis would disgrace their families, emphasizing the importance of maintaining their social standing within the family [13,32]. Such fear and stigma around breast cancer diagnosis are possible in Vietnamese communities and thus require further research attention. Further, although advice on BSE remains controversial, in environments with limited resources where women lack opportunities for clinical examination, BSE is the best alternative for the early detection of breast cancer. Increased focus on opting for BSE based on the four-step ladder motivation model (i.e., taking opportunities, clarifying confusion, maintaining health, and illness monitoring) is suggested for BSE interventions in young Vietnamese populations to increase risk awareness and to reduce cultural beliefs regarding breast cancer [33].

In this study, more than half of all the participants, including both younger (69.5\%) and older (53.3\%) women, believed that they would not get breast cancer if they took good care of themselves. As reported in a recent study of Asian and African women living in Australia [34], this cultural factor plays a key role in shaping breast cancer beliefs and screening behaviors in women. For example, certain groups of women do not realize that they are at risk of getting the disease even though they feel healthy. This finding is similar to a study by Shang, Beaver, and Campbell [32], in which Chinese women recognized the importance of self-care to promote health and prevent illness; however, they did not pay much attention to BSE. Importantly, even in the younger age group in the current study, perceptions regarding self-help techniques were considerably impacted by cultural beliefs, indicating that young women still need to be educated to increase BCS awareness. Using a variety of channels, such as healthcare providers and the media, the development of culturally appropriate health education to increase BCS awareness and to reduce cultural beliefs regarding breast cancer is recommended.

Prior studies [35-37] including community-based population surveys in low- and middle-income countries showed consistent results-that participants' BCS awareness was significantly lower than it was in developed countries. In a recent review of 53 studies conducted in resource-limited countries [11], lack of knowledge and low awareness of BCS were key barriers to women obtaining cancer screening. This may be a possible consequence of their lower living standards and less supportive public health service. Therefore, it is necessary to provide more effective strategies to promote health service access and health screening to vulnerable and underserved populations who have erroneous cultural beliefs concerning BCS.
The current findings have several practical and research implications. The extent of the breast cancer cultural beliefs identified in this study would be informative to healthcare providers working in community health centers in Vietnam. Healthcare providers should competently provide community education concerning the early detection of breast cancer and diagnostic techniques for BCS practices, which are lacking in Vietnam [4]. This indicates the need for a training program for healthcare providers working in community health centers. Healthcare providers also need to understand the factors influencing women's cultural beliefs such as age and income level when establishing educational programs. In addition, BCS should be promoted early in clinical settings since Vietnamese women are more likely to be diagnosed with later-stage breast cancer than are Western women. This may require easier access to clinical settings in rural areas at a low cost.

The major strength of our study is that it is the first to assess cultural beliefs in Vietnamese women using a validated instrument that can contribute to the late detection of breast cancer and inform future studies in other areas in Vietnam and in other Asian countries. Nevertheless, there are several limitations to our study. The convenience sampling and cross-sectional design limits the generalizability of our study findings and do not allow for the identification of casual relationships among study variables. Second, the retrospective findings only provide a general overview of cultural beliefs and the factors associated with them. Further, our samples were recruited from one rural province, where residents have a low average income. Therefore, the study findings may not be generalized to other areas in Vietnam, especially to urban cities where residents have a higher income, and may not fully explain the cultural beliefs of all Vietnamese women. Future studies should employ larger samples with more complex sampling methods. Additional studies using larger samples and random sampling from other rural provinces may be helpful to identify the cultural beliefs of more Vietnamese women. Lastly, although we used a rigorous translation process including cognitive interviews, there is a possibility that we misinterpreted some concepts or did not include items that are specific to Vietnamese women since the original instrument was developed for minorities in the United States. More rigorous psychometric testing of the instrument is recommended for future studies.

\section{Conclusions}

This study makes several contributions to the current cultural beliefs related BCS in Vietnamese rural women. We found the level of cultural beliefs about breast cancer in Vietnamese women were generally low, and also found that younger women and women with lower 
income had more erroneous cultural beliefs. Therefore, the findings support the need for health education that addresses the early detection of breast cancer including BSE and guidance on evidence-based, up-to-date, intervention measures that target women's cultural beliefs, especially women aged younger than 40 years. Finally, it is vital for public health educators and administrators to understand that cultural beliefs about breast cancer in Vietnamese women differ by generation. Accordingly, a targeted approach to health education and BCS strategies is needed to support different generations of Vietnamese women to optimize breast cancer screening.

\section{Additional file}

Additional file 1: Breast Cancer Cultural Beliefs Scale. (DOCX $16 \mathrm{~kb}$ )

\section{Abbreviations}

BCS: Breast Cancer Screening; BSE: Breast Self-Examination

\section{Acknowledgements}

Not applicable.

\section{Authors' contributions}

$J G K, H K L, H C H, C E F$, and EMK conducted the research from conception to the writing of the final draft of the article. All authors read and approved the final manuscript.

\section{Funding}

The authors disclose receipt of the following financial support for the research, authorship, and/or publication of this article: a faculty-student research grant from the College of Nursing at Yonsei University (no. 6-20160050). The funding body had no role in the design of the study, data collection, analysis, interpretation of data, or in writing the manuscript.

\section{Availability of data and materials}

The datasets used and/or analyzed during the current study are not publicly available due to their contents containing personal information. However, redacted version may be made available from the corresponding author on reasonable request.

\section{Ethics approval and consent to participate}

Before data collection, the trained data collectors explained the aim of the study and obtained written consent from all participants. Participation in the study was voluntary, and each participant was able to withdraw from the study at any time. The institutional research board (IRB) of Yonsei University approved this study (no. 2016-0048-1). The Department of Health and local women's council of the Quang Tri Province in Vietnam authorized the study. The Department of Health in the Quang Tri Province did not request to submit IRB.

\section{Consent for publication}

Not applicable.

\section{Competing interests}

The authors declare that they have no competing interests.

\section{Author details}

'Department of Nursing, Hoseo University, 20, 79 Street, Hoseo-ro, Baebang-eup, Asan, Chungcheongnam-do 31499, South Korea. ${ }^{2}$ Red Cross College of Nursing, Chung-Ang University, 84 Heukseok-ro, Dongjak-ku, room 401-3, building 106, Seoul 06974, South Korea. ${ }^{3}$ College of Nursing, Mo-Im Kim Nursing Research Institute, Yonsei University, 50 Yonsei-ro, Seodaemun-gu, Seoul 03722, South Korea. ${ }^{4}$ College of Nursing, University of Illinois at Chicago, 845 S. Damen Ave., M/C 802 room 606, Chicago, IL 60612,
USA. ${ }^{5}$ Department of Nursing, Sunlin University, 30 Chogok-gil, 36beon-gil, Heunghae-eup, Buk-gu, Pohang, Gyeongsangbuk-do 37560, South Korea.

Received: 17 April 2018 Accepted: 4 June 2019

Published online: 11 June 2019

\section{References}

1. Global Burden of Disease Cancer Collaboration. Global, regional, and national cancer incidence, mortality, years of life lost, years lived with disability, and disability-adjusted life-years for 32 cancer groups, 1990 to 2015: a systematic analysis for the global burden of disease study. JAMA Oncol. 2017;3(4):524-48.

2. Trieu P, Mello-Thoms C, Brennan P. Female breast cancer in Vietnam: a comparison across Asian specific regions. Cancer Bio Med. 2015;12(3): 238-45. https://doi.org/10.7497/j.issn.2095-3941.2015.0034.

3. Vietnamese Government. National cancer control project, period of 20082010 [in Vietnamese]. Hanoi: Ministry of Health; 2007.

4. Jenkins C, Minh LN, Anh TT, Ngan TT, Tuan NT, Giang KB, Hoat LN, Lohfeld L, Donnelly M, Van Minh H, Murray L. Breast cancer services in Vietnam: a scoping review. Glob Health Action. 2018;11(1):1435344. https://doi.org/10 1080/16549716.2018.1435344

5. Donnelly TT, Al Khater A, Al-Bader SB, Al Kuwari MG, Al-Meer N, Malik M, Singh R, Chaudhry S, Fung T. Beliefs and attitudes about breast cancer and screening practices among Arab women living in Qatar: a cross-sectional study. BMC Womens Health. 2013;13(13):49. https://doi.org/10.1186/14726874-13-49.

6. Pasick RJ, Burke NJ. A critical review of theory in breast cancer screening promotion across cultures. Annu Rev Public Health. 2008:29:351-68.

7. Azaiza F, Cohen M. Between traditional and modern perceptions of breast and cervical cancer screening: a qualitative study of Arab women in Israel. Psychooncology. 2008;17(1):34-41.

8. Harper C. Vietnam noncommunicable disease prevention and control programme 2002-2010. Implementation review for the WHO. Geneva: WHO Press; 2011. http://www.wpro.who.int/vietnam/topics/chronic_diseases/ vietnam noncommunicable disease_prevention_and_control_program 2002_2010_imple_review.pdf.

9. Lee FH. Intention to receive breast cancer screening and related factors of influence among Vietnamese women in transnational marriages. J Nurs Res. 2018;26(2):112-22. https://doi.org/10.1097/jnr.0000000000000210.

10. Rivera-Franco MM, Leon-Rodriguez E. Delays in breast Cancer detection and treatment in developing countries. Breast Cancer (Auckl). 2018;12: 1178223417752677. Published 2018 Jan 8. https://doi.org/10.1177/ 1178223417752677 .

11. Islam RM, Billah B, Hossain MN, Oldroyd J. Barriers to cervical Cancer and breast Cancer screening uptake in low-income and middle-income countries: a systematic review. Asian Pac J Cancer Prev. 2017:18(7):1751-63.

12. Liang W, Yuan E, Mandelblatt JS, Pasick RJ. How do older Chinese women view health and cancer screening? Results from focus groups and implications for interventions. Ethn Health. 2004;9(3):283-304.

13. Bedi M, Devins GM. Cultural consideration for south Asian women with breast cancer. J Cancer Surviv. 2016;10(1):31-50. https://doi.org/10.1007/ s11764-015-0449-8.

14. Nguyen $A B$, Clark $T$. The role of acculturation and collectivism in cancer screening for Vietnamese American women. Health Care Women Int. 2014; 35(10):1162-80.

15. D'Andrade R. Human motives and cultural models. Cambridge: Cambridge University Press; 1992.

16. Koltko-Rivera ME. The psychology of worldviews. Rev Gen Psychol. 2004;8(1): $3-58$

17. Iwelunmor J, Newsome $V$, Airhihenbuwa C. Framing the impact of culture on health: a systematic review of the PEN-3 cultural model and its application in public health research and interventions. Ethn Health. 2014; 19(1):20-46. https://doi.org/10.1080/13557858.2013.857768.

18. Pruitt SL, Shim MJ, Mullen PD, Vernon SW, Amick BC 3rd. Association of area socioeconomic status and breast, cervical, and colorectal cancer screening: a systematic review. Cancer Epidemiol Biomark Prev. 2009:18(10):2579-99. https://doi.org/10.1158/1055-9965.EPI-09-0135.

19. Kim EM, Lee H, Kim JG, Ho TV, Huong NTT, Mai TTN, Son NT. Using the stage-based approaches to predict breast self-examination among rural Vietnamese women. Asia Pac J Public Health. 2019:1-10. https://doi.org/10. $1177 / 1010539519849326$ 
20. Ferrans C, Rauscher G, Akpan B, Johnson T, Ramirez D, Willis M, Warnecke R. Cultural beliefs contributing to disparities in later-stage breast cancer among African American, Latina, and Caucasian women. Qual Life Res. 2007; 16(Suppl, A):27.

21. Ferrans C, Rauscher G, Akpan B, Johnson T, Ramirez D, Willis M, Warnecke R. Cultural beliefs contributing to disparities in later-stage breast cancer among newly diagnosed African, American, Latina, and Caucasian women. Oncol Nurs Forum. 2007;34(1):180-1.

22. Furukawa R, Driessnack M, Colclough Y. A committee approach maintaining cultural originality in translation. Appl Nurs Res. 2014;27(2):144-6.

23. Vietnam Inequality Report. Oxfam briefing paper; 2017. p. 37. https:// vietnam.oxfam.org/sites/vietnam.oxfam.org/files/file_attachments/ Vietnam\%20Inequality\%20Report_ENG.pdf.

24. General statistics office of Vietnam. http://www.gso.gov.vn/default_en. aspx?tabid=474\&idmid=3\&ltemID $=12700$.

25. Siaki LA, Loescher $L$, Trego LL. Synthesis strategy: building a culturally sensitive mid-range theory of risk perception using literary, quantitative, and qualitative methods. J Adv Nurs. 2013;69(3):726-37. https://doi.org/10.1111/j. 1365-2648.2012.06096.x.

26. Riegel B, Jaarsma T, Stromberg A. A middle-range theory of self-care of chronic illness. Adv Nurs Sci. 2012;35(3):194-204.

27. Saint Arnault D. Cultural determinants of help seeking: Amodel for research and practice. Res and Theory Nurs Pract. 2009;23(4):259-78.

28. Rauscher G, Ferrans CE, Kaiser K, Campbell R, Calhoun E, Warnecke R. Misconceptions about breast lumps and delayed medical presentation in urban breast cancer patients. Cancer Epidemiology Biomarkers Preview. 2010;19(3):640-7. https://doi.org/10.1158/1055-9965.EPI-09-0997.

29. Phuong DT, Claudia MT, Patric CB. Female breast cancer in Vietnam: a comparison across Asian specific regions. Cancer Biol Med. 2015;12:238-45. https://doi.org/10.7497/j.issn.2095-3941.2015.0034.

30. Liu LY, Wang YJ, Wang F, Yu LX, Xiang YJ, Zhou F, Li L, Zhang Q, Fu QY, Ma ZB, Gao DZ, Li YY, Yu ZG. Factors associated with insufficient awareness of breast cancer among women in northern and eastern China: a case-control study. BMJ Open. 2018;8(2):e018523. https://doi.org/10.1136/bmjopen-2017018523.

31. Lin Y, Wang T, Tung H, Furze G. Coronary heart disease beliefs and misconceptions among cardiac patients and people with chronic illness. Open J Nurs. 2012;2:1-7.

32. Shang C, Beaver K, Campbell M. Social cultural influences on breast cancer views and breast health practices among Chinese women in the United Kingdom. Cancer Nurs. 2015;38(5):343-50. https://doi.org/10.1097/NCC. 0000000000000195 .

33. Yang R, Huang L, Hsieh Y, Chung U, Huang C, Bih H. Motivations and reasons for women attending a breast self-examination training program: a qualitative study. BMC Womens Health. 2010;(23):10. https://doi.org/10.1186/ 1472-6874-10-23.

34. Lam M, Kwok C, Lee M. Prevalence and sociodemographic correlates of routine breast cancer screening practices among migrant-Australian women. Aust and N Z J Public Health. 2018;42(1):98-103. https://doi.org/10. 1111/1753-6405.12752.

35. Forbes $\sqcup$, Atkins L, Thurnham A, Layburn J, Haste F, Ramirez AJ. Breast cancer awareness and barriers to symptomatic presentation among women from different ethnic groups in East London. Br J Cancer. 2011;10(5):1474-9. https://doi.org/10.1038/bjc.2011.406.

36. Aydogan U, Doganer YC, Kilbas Z, Rohrer JE, Sari O, Usterme N, Yuksel S, Akbulut H, Balkan SM, Saglam K, Tufan T. Predictors of knowledge level and awareness towards breast cancer among Turkish females. Asian Pac J Cancer Prev. 2015;16(1):275-82.

37. Khan TM, Leong JP, Ming LC, Khan AH. Association of knowledge and cultural perceptions of Malaysian women with delay in diagnosis and treatment of breast cancer: a systematic review. Asian Pac J Cancer Prev. 2015;16(13):5349.

\section{Publisher's Note}

Springer Nature remains neutral with regard to jurisdictional claims in published maps and institutional affiliations.

Ready to submit your research? Choose BMC and benefit from:

- fast, convenient online submission

- thorough peer review by experienced researchers in your field

- rapid publication on acceptance

- support for research data, including large and complex data types

- gold Open Access which fosters wider collaboration and increased citations

- maximum visibility for your research: over $100 \mathrm{M}$ website views per year

At BMC, research is always in progress.

Learn more biomedcentral.com/submissions 